\title{
Horticultural Therapy Program Based on Health Care Education for Stress Reduction of Hypertensive Patients
}

\author{
Soo Seon Jung ${ }^{1}$, Sin Ae Park ${ }^{1,2}$, Yun Ah $\mathrm{Oh}^{1}$, and Ki Cheol Son ${ }^{1,2 *}$ \\ ${ }^{1}$ Horticultural Therapy, Graduate School of Agriculture and Animal Science, Konkuk University, Seoul 05029, South Korea \\ ${ }^{2}$ Department of Environmental Health Science, Sanghuh College of Life Science, Konkuk University, Seoul 05029, South Korea
}

\begin{abstract}
This study was conducted to analyze the effects of horticultural therapy program based on health care education on quality of life, stress, depression and anxiety of hypertensive patients, and to find effects on ability to control hypertension by continuing health care education and horticulture education. Subjects were 60 adult hypertension patients aged 30 to 64 at a hospital in K-gu, Seoul, aged 30 to 64 . Experimental group of 30 patients received horticultural therapy program and control group of 30 patients did not receive horticultural therapy program. The horticultural therapy program was conducted for 60 minutes per session, twice a week, and total 8 times. This study was performed from 1. Aug. to 31. Oct. in 2015. Each session was based on contents of basic health care education and horticultural education. The programs were verified by 5 specialists in related fields ( 1 doctor, 2 nurses, 2 horticultural therapists). To prove effects of horticultural therapy program, patients' stress, depression, anxiety, quality of life and knowledge of hypertension and horticulture were estimated 3 times(before, after and 1 month after the experiment). SPSS (Version 22 for Windows) was used for t-test of independent sample, which analyzes demographic information and verifies homogeneity, and for t-test of matching sample which shows different effects between groups. As the results, horticultural therapy program based on health care education made significant positive effects on stress and quality of life of hypertensive patients. Moreover, the horticultural therapy program improved knowledge on horticulture and hypertension. However, there were no significant changes in control group. This result shows that the horticultural therapy program based on health care could relive stress and improve quality of life.
\end{abstract}

Key words: gardening, human issues in horticulture, hypertension education, socio horticulture

\section{I . Introduction}

Hypertension is one of the major diseases that increases stroke, myocardial infarction, renal failure, congestive heart failure, atherosclerosis, and dementia (Forette et al., 1998). The prevalence of hypertension among adults aged 30 or above in Korea has increased from $24.6 \%$ in 2007 to $29.0 \%$ in 2012 (Korean National Statistical Office, 2012). Most hypertensive patients do not perceive their state until the complications break out (Kim et al., 2000; Jo et al., 2004), and the level of care also turned out to be low (Nine et al., 2003).

In Korea, the Ministry of Health and Welfare established the Comprehensive Plan for Cardio- and Cerebrovascular Diseases

Received on September 9, 2016. Revised on December 6, 2016.

Accepted on April 3, 2017.

*Comesponding author: kcson@konkuk.ac.kr

This paper was written as part of Konkuk University's research support program for its faculty on sabbatical leave in 2016. in 2011, through which it created and distributed the 9 Rules of Life to Prevent and Manage - and Cerebrovascular Diseases for people to prevent and manage such diseases (Ministry of Health and Welfare in Korea, 2014). However, the national hypertension management program currently focuses only on short-term blood pressure management of hypertensive patients, with limitations that make it difficult to be carried on without the help of medical professionals, such as doctors, nurses, sports curers, and dietitians (Lee, 2004; So and Lee, 2010).

Advanced countries like the US, Canada and Japan have been providing education on sustainable management of diseases that require chronic management such as hypertension, diabetes and metabolic syndrome since the 1980s as part of their health promotion programs.

Meanwhile, according to research data on the characteristics of hypertensive patients, they have more chronic mental issues such as stress, depression and anxiety disorders than ordinary people (Jo et al., 1997). Hypertensive patients suffer from 
higher stress levels than ordinary people (Lee and Han, 2000), and cannot adapt well to stress due to chronic mental conflicts (Jo et al., 1997). Stress is a mental and physical state of tension that occurs when one is exposed to a situation that is difficult to adjust (Lee et al., 2012). In other words, stress affects not only psychiatric diseases such as depressive and anxiety disorders but also physical diseases such as cardiovascular and digestive diseases (Han, 2003).

Hypertensive patients also have mental issues like depressive and anxiety disorders aside from stress, and depression has a negative impact on individual emotions and especially leads to deep sorrow and deprives one of interest or joy in daily life (American Psychiatry Association, 2017). Lukkarinen and Hentinen (1997) stated that patients with cardiovascular diseases including hypertension suffer from mental burden like stress, anxiety and depression due to their diseases, and Ginty et al. (2013), Jeon and Kim (2012), and Saboya et al. (2010) also proved that hypertensive patients have high levels of anxiety and depression.

Furthermore, hypertensive patients turned out to have a lower quality of life than people without hypertension (Park et al., 1992; Bardage et al., 2003; Li et al., 2005). For hypertensive patients, quality of life is an indicator that reveals their subjective evaluation to analyze the effects of the disease or treatment on the patients in physical, mental and social aspects (Kim, 1997). Stress and quality of life are closely related (Clark et al., 2011), and in particular, stress management of patients with chronic diseases affects their quality of life (Han, 2003). Li et al. (2005) controlled age, gender, socio-demographic factors and complications in their study on the quality of health-related life of hypertensive patients, and the results showed that hypertensive patients had lower quality of healthrelated life than the normal group in all areas. However, the current health care education focuses only on blood pressure management, with no program to manage stress for hypertensive patients.

In terms of research on horticultural therapy, it turned out that horticultural therapy programs helped lower blood pressure or pulse of people with intellectual disabilities (Doxon et al., 1987) and ordinary people (Owen, 1994; Coleman and Mattson, 1995; Lohr et al., 1996). However, there was no research on horticultural therapy that took an approach to solve mental problems like stress, depression, anxiety and quality of life for hypertensive patients.

Therefore, this study was conducted to determine the effects of horticultural therapy programs applying health care education for hypertensive patients on alleviation of their stress, anxiety and depression and improvement of quality of life.

\section{Research method}

\section{Subjects}

This study is conducted on hypertensive patients that are outpatients of Konkuk University Medical Center located in Gwangjin-gu. To recruit participants, a notice including descriptions about the horticultural therapy program was posted on the bulletin board of the outpatient department at the hospital, after which the doctor in charge explained the contents of the program to hypertensive patients. Patients were accepted as participants in order of application. They were hypertensive patients from age 30 to 64 , which aged showing high prevalence of hypertension according to the Korea Centers for Disease Control and Prevention (2014). They were to show systolic pressure of $140 \mathrm{mmHg}$ or lower and diastolic pressure of 90 $\mathrm{mmHg}$ or lower in resting blood pressure, have received consistent prescriptions of antihypertensive drug in the last 6 months if they take medication, be in self-management such as lifestyle improvement even though they are diagnosed with hypertension by the doctor, and be able to participate in at least 6 of total 8 sessions. Hypertensive patients that are pregnant or nursing, or have complications that restrict their everyday life (e.g. cardiac failure, myocardial infarction, cerebral infarction, etc.) were excluded from this study. Among total 60 hypertensive patients that were ultimately selected, those who picked number one in the draw were assigned to the experimental group participating in the horticultural therapy program, while those who picked number two were assigned to the control group. Before carrying out the first session of the program, they signed the consent that described the objective and method of this program in the orientation, and their demographic data such as age, gender, education level, religion, etc. were collected through a questionnaire (Table 1). To measure blood pressure, the subjects were to relax in a sitting position for about 10 
Table 1. Horticultural therapy program based on health care education for hypertensive patients.

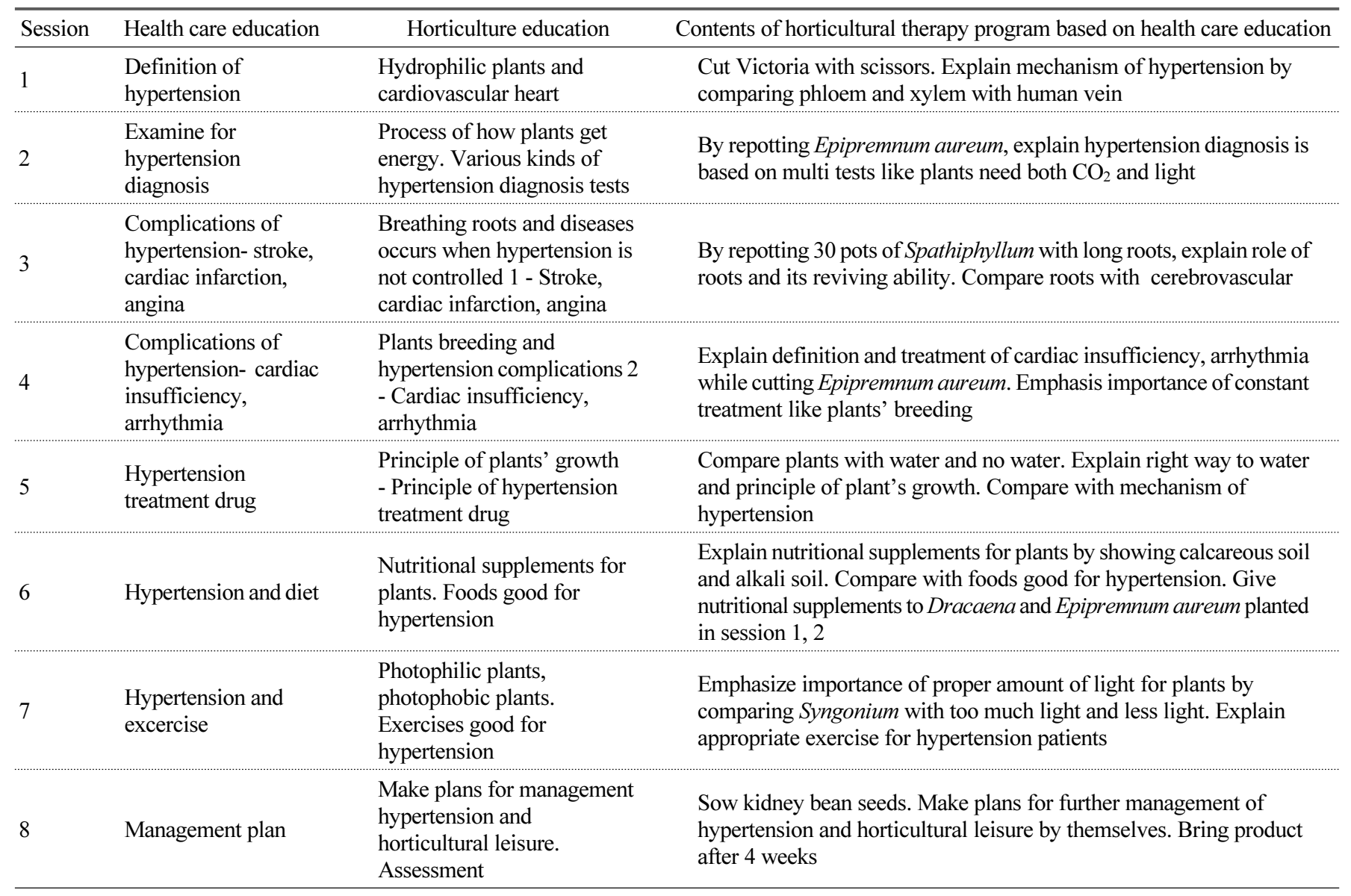

minutes upon arriving at the laboratory, after which their blood pressure was measured with their arms and heart positioned in parallel. A stethoscope and mercury sphygmomanometer (Speidel and Keller, Germany) were used to put on a cuff on the upper left arm, and the stethoscope was fixated on the brachial artery. The systolic and diastolic blood pressures were measured twice at a five-minute interval, and the average was calculated.

This study was deliberated and approved by the Institutional Review Board of Konkuk University (approval no. 7001355201406-HR-024).

\section{Research environment}

This horticultural therapy program was carried out twice a week from August to September 2014 in total 8 sessions (60 minutes on average per session). This program was implemented in a lecture hall (about 20 pyeong) with the average indoor temperature of $20-25^{\circ} \mathrm{C}$ and relative humidity of $70-80 \%$. In each session, the participants performed the horticultural activities sitting around a rectangular desk in groups of 5-6 members. The program was carried out by one main therapist (Korean Horticultural Therapy Association Level 2 certification, master's program in horticultural therapy) and two assistant therapists (Korean Horticultural Therapy Association Level 2 certification, master's program in horticultural therapy). Patients participating in the program showed a $100 \%$ attendance rate.

3. Development of horticultural therapy program based on health care education to relieve stress for hypertensive patients

This horticultural therapy program consists of total 8 sessions, which is the commonly used number of sessions for health care 
education programs with reference to total 28 meta-analysis studies on the effects of hypertension health care education programs analyzed by Lee (2003).

The program consisted of health care education and horticulture education/activities of hypertensive patients in each session (Table 1). The contents of education on the symptom and management of hypertension were selected based on the contents of health care education for hypertensive patients published by Korea Centers for Disease Control and Prevention (2012). Basic contents about hypertension selected such as definition of hypertension, diagnosis, complications, drugs, diet and exercise were provided according to the topic of the program in each session.

Moreover, for horticulture education, basic contents of horticulture based on daily life horticulture such as basic structure of plants, photosynthesis, roots, reproduction, soil and light were provided, along with horticultural activities related to the contents of education on theories. The plants used were those that can be easily obtained year-round: Dracaena deremensis N.E.Br. var. Warneckii (Dracaena-victoria), Spathiphyllum cannifolium (Dryand.) Schott (Peace lily), Syngonium podophyllum Schott (Syngonium), Scindapusus aureus / Epipremnum aureum (Scindapsus).

The contents of this program were modified and improved with advice from total 5 related experts ( 1 clinical professor in cardiology, 2 nurses in cardiology, and 2 horticultural therapists with Level 1 certification) (Table 1).

\section{Assessment and analysis}

\section{1) Assessment tool}

To verify the effects of this program, this study measured stress, quality of life, anxiety, depression, and knowledge in hypertension, and knowledge in horticulture of the patients that participated in this study (experimental group, control group), before and after the horticultural therapy program as well as 1 month later. The experimental group also assessed their satisfaction in the horticultural therapy program.

\section{(1) Stress scale}

Stress was measured with the Global Assessment of Recent Stress (GARS) designed by Linn in 1985 and standardized by
Koh (1988) in Korean. The tool consists of 8 items that can assess the perception of stress in the last week, such as work, pressure about job and school, pressure about personal relations, pressure about changes in personal relations, pressure about non-daily things, and overall pressure during the week. It is rated on a 10-point Likert scale, with higher scores showing higher level of perceiving stress. The reliability of this questionnaire was 0.81 in Cronbach's alpha.

\section{(2) Quality of life scale}

Quality of life was measured with the World Health Quality of Life Assessment Instrument-100 (WHOQOL-100) developed by WHO and revised by Min et al. (2000) in Korean. It consists of total 24 items in 4 categories: 8 items in physical health, 6 items in psychological health, 2 items in social relationships, and 8 items in environmental health. Each item is rated on a 5 -point scale, with higher scores showing higher quality of life. The reliability of this questionnaire was 0.89 in Cronbach's alpha.

\section{(3) Depression scale}

Depression was measured with the tool developed by Beck et al. (1961) and adapted by Lee and Song (1991), consisting of total 21 items. It is rated on a 4-point Likert scale, with higher scores showing more severe symptoms of depression. The sum of the scores that is 16 points or higher may indicate depression, but there are limitations in diagnosing someone with depression or determining the severity with this score alone. The scores for depressive state are classified into no depression (0-9 points), mild depression (10-15 points), moderate depression (16-23 points), and severe depression (24-63 points). The reliability of this questionnaire was 0.79 in Cronbach's alpha.

\section{(4) Anxiety scale}

Anxiety was measured with the State-Trait Anxiety Inventory (STAI) developed by Spielberger et al. (1970) and standardized by Kim (1979) in Korean. It consists of two factors: state anxiety that is currently felt, and trait anxiety that is generally felt by people. There are total 40 items, with 20 items for each of the two sub-factors. It is rated on a 4-point Likert scale, with higher scores indicating higher level of anxiety (Oh et al., 2012).

The reliability of this questionnaire is presented with 
Cronbach's alpha of 0.93 for state anxiety and 0.91 for trait anxiety in the study by Kim (2011).

\section{(5) Assessment of knowledge in hypertension}

Knowledge in hypertension is measured with total 7 items, one each per session, based on the contents learned in the health care education of this study. The items are multiplechoice questions with five choices for the answer, with reference to the textbook on hypertension health care education (basic and advanced) published by Korea Centers for Disease Control and Prevention (2012) and the hypertension knowledge assessment tool by Lee (1998) and Jang (2003). They were supervised by one clinical professor in cardiology at a medical school.

\section{(6) Assessment of knowledge in horticulture}

Knowledge in horticulture is measured with total 7 items, one each per session, based on the contents learned in the horticulture education of this study. The items are multiplechoice questions with five choices for the answer, with reference to the horticultural knowledge assessment survey by Jo (2013) on questions about the basic structure of plants, photosynthesis, roots, unisexual propagation of plants, soil, and light. They were supervised by two professors in horticultural science.

\section{(7) Satisfaction for the horticultural therapy program}

To assess satisfaction in the horticultural therapy program implementing hypertension health care education, a survey was conducted only among the experimental group after the last session of the program. To survey the satisfaction in this program, items related to this program were modified and improved among those in the studies by Jeong and Huh (2011), Kwon (2012), Park et al. (2016) with regard to general preference of horticulture and morphological preference of horticultural plants. Total 7 items were ultimately used in the questionnaire.

\section{2) Analysis method}

To compare the demographic data of two groups (experimental and control group) and verify the homogeneity between the groups through preliminary assessment, SPSS (Version 22 for Windows) was used to conduct an independent samples t-test at the $p<.05$ level. To determine the changes in stress, quality of life, depression, anxiety, knowledge in hypertension, and knowledge in horticulture of the experimental and control group before and after the horticultural therapy program as well as 1 month later, SPSS (Version 22 for Windows) was used to conduct a paired t-test at the $p<.05$ level. For data analysis of the satisfaction survey on the program, Microsoft Excel (Office 2007; Microsoft Corp., Redmonf, WA) was used for descriptive statistics on the mean, standard deviation and percentage of each collected item.

\section{Results and discussion}

1. General characteristics of the control and experimental group and homogeneity testing

The participants in this study are total 60 adult hypertensive patients (30 in the experimental group and 30 in the control group) registered as outpatients of the department of cardiology at Konkuk University Medical Center in Gwangjin-gu. Table 2 shows the general characteristics of the two groups.

The average height of the subjects was $157.4 \pm 8.5 \mathrm{~cm}$ for the experimental group and $158.9 \pm 5.3 \mathrm{~cm}$ for the control group, and the average weight was $57.7 \pm 10.2 \mathrm{~kg}$ for the experimental group and $58.4 \pm 6.4 \mathrm{~kg}$ for the control group, showing no significant difference. The average blood pressure was $126 \pm$ $16.42 \mathrm{mmHg}$ for the experimental group and $127 \pm 16.01 \mathrm{mmHg}$ for the control group in systolic pressure, and $77 \pm 10.68 \mathrm{mmHg}$ for the experimental group and $76 \pm 10.46 \mathrm{mmHg}$ for the control group in diastolic pressure, showing no significant difference and thereby proving that the two groups are homogeneous.

To determine the basic level of information about hypertension and knowledge in health care education of the participants, this study compared the time passed after being diagnosed with hypertension, and experience in health care education related to hypertension. The result showed that there was no significant difference between the two groups ( $p<.05$, Table 2). Most subjects were diagnosed with hypertension in less than a year, and they generally had none or one experience receiving health care education about hypertension. For the question about experience in horticultural activities, both groups turned out to have experience. 
Table 2. Demographic characteristics of the hypertension patients who participated in the study about horticultural therapy (HT) program based on health care education for stress reduction of hypertension patients.

\begin{tabular}{|c|c|c|c|c|}
\hline \multicolumn{2}{|l|}{ Variables } & HT $(n=30)$ & Control $(n=30)$ & Probability \\
\hline & \multicolumn{4}{|c|}{ Average $(\mathrm{SD})$} \\
\hline \multicolumn{2}{|l|}{ Height $(\mathrm{cm})$} & $158.9(8.5)$ & $157.4(5.3)$ & 0.4 \\
\hline \multicolumn{2}{|l|}{ Weight $(\mathrm{kg})$} & $58.4(10.2)$ & $57.7(6.4)$ & 0.7 \\
\hline \multicolumn{2}{|c|}{ The number of times about hypertension education } & $0.5(1.0)$ & $0.3(0.8)$ & 0.5 \\
\hline \multirow{3}{*}{$\begin{array}{ll}\text { Blood pressure } & \begin{array}{l}\text { Systolic pressure } \\
\text { Diastolic pressure }\end{array} \\
\end{array}$} & & $127(16.4)$ & $127(16.0)$ & 1.0 \\
\hline & & $77(10.7)$ & $76(10.5)$ & 0.9 \\
\hline & & & & \\
\hline \multirow{2}{*}{ Gender } & Female & $26(86.7)$ & & \multirow{2}{*}{$29(96.7)$} \\
\hline & Male & $4(13.3)$ & & \\
\hline \multirow{4}{*}{ Age } & $30-39$ & $0(0)$ & & \multirow{4}{*}{$2(6.7)$} \\
\hline & $40-49$ & $2(6.7)$ & & \\
\hline & $50-59$ & $9(30.0)$ & & \\
\hline & $60-65$ & $19(63.3)$ & & \\
\hline \multirow{4}{*}{ Diagnosis of period (year) } & Less than 1 & $13(43.3)$ & $18(60.0)$ & \multirow{4}{*}{0.6} \\
\hline & $1-4$ & $10(33.3)$ & $6(20.0)$ & \\
\hline & $5-9$ & $4(13.3)$ & $4(13.3)$ & \\
\hline & More than 10 & $3(10.0)$ & $2(6.7)$ & \\
\hline \multirow{2}{*}{ Experience of hypertension education } & Yes & $5(16.7)$ & $8(26.7)$ & \multirow{2}{*}{0.5} \\
\hline & No & $25(83.3)$ & $22(73.3)$ & \\
\hline \multirow{5}{*}{$\begin{array}{l}\text { Interest of hypertension } \\
\text { management }\end{array}$} & Most & $13(43.3)$ & $8(26.7)$ & \multirow{5}{*}{0.7} \\
\hline & More & $7(23.3)$ & $8(26.7)$ & \\
\hline & a little & $7(23.3)$ & $9(30.0)$ & \\
\hline & No & $1(3.3)$ & $2(6.7)$ & \\
\hline & Absolutely no & $2(6.7)$ & $3(10.0)$ & \\
\hline \multirow{4}{*}{ Smoking, alcohol } & Both of all & $2(6.7)$ & $0(0)$ & \\
\hline & Only smoking & $0(0)$ & $2(6.7)$ & \\
\hline & Only alcohol & $6(20.0)$ & $5(16.7)$ & 0.3 \\
\hline & Both of nothing & $22(73.3)$ & $23(76.7)$ & \\
\hline & Yes & $27(90.0)$ & $26(86.7)$ & \\
\hline Experience of plant-growing activity & No & $3(10.0)$ & $4(13.3)$ & 0.7 \\
\hline & Botanical garden & $1(3.3)$ & $2(6.7)$ & \\
\hline & School & $4(13.3)$ & $3(10.0)$ & \\
\hline Information source of horticultural education & TV or internet & $8(26.7)$ & $9(30.0)$ & 0.8 \\
\hline & Illustrated plant book & $1(3.3)$ & $0(0)$ & \\
\hline & Self-study & $16(53.3)$ & $16(53.3)$ & \\
\hline & Middle school & $5(16.6)$ & $6(20.0)$ & \\
\hline & High school & $10(33.3)$ & $9(30.0)$ & \\
\hline Education & University & $14(46.7)$ & $15(50.0)$ & 0.8 \\
\hline & Graduate school & $1(3.3)$ & $0(0)$ & \\
\hline & Unmarried & $0(0)$ & $4(13.3)$ & \\
\hline & Married & $23(76.7)$ & $23(76.7)$ & \\
\hline Marit status & Remarried & $1(3.3)$ & $0(0)$ & 0.1 \\
\hline & Others & $6(20.0)$ & $3(10.0)$ & \\
\hline & Buddist & $8(26.7)$ & $7(23.3)$ & \\
\hline & Christian & $8(26.7)$ & $4(13.3)$ & \\
\hline Religion & Roman catholic & $11(36.7)$ & $18(60.0)$ & 0.4 \\
\hline & Atheist & $2(6.7)$ & $1(3.3)$ & \\
\hline & Others & $1(3.3)$ & $0(0)$ & \\
\hline Fmployment & Yes & $11(36.7)$ & $15(50.0)$ & 04 \\
\hline Employment & No & $19(63.3)$ & $15(50.0)$ & 0.4 \\
\hline & Less than $1,000,000$ & $2(6.7)$ & $3(10.0)$ & \\
\hline & $1,000,000-1,999,999$ & $13(43.3)$ & $12(40.0)$ & \\
\hline Monthly income (Won) & $2,000,000-2,999,999$ & $2(6.7)$ & $7(23.3)$ & 0.3 \\
\hline & $3,000,000-3,999,999$ & $5(16.7)$ & $5(16.7)$ & \\
\hline & More than $4,000,000$ & $8(26.7)$ & $2(6.7)$ & \\
\hline & Apartment building & $24(80.0)$ & $22(73.3)$ & \\
\hline Housing & Detached house & $5(16.7)$ & $6(20.0)$ & 0.8 \\
\hline & Tenement house & $1(3.3)$ & $2(6.7)$ & \\
\hline
\end{tabular}


2. Effects of the horticultural therapy program

1) Psychological changes in hypertensive patients

\section{(1) Stress}

The results of this study showed that the experimental group had a significant decrease in the stress levels after the horticultural therapy program and 1 month later (Fig. 1). But the control group showed no significant difference (Fig. 1). This horticultural therapy program provided hypertensive patients with information on understanding and managing hypertension and increased the level of knowledge in hypertension, thereby reducing stress (Jang, 2016). Moreover, plants used in this program were green foliage plants, and activities using such green plants gave mental security to humans (Kaplan, 1973; Moore, 1989), and brought stability to the autonomic nervous system, thereby reducing stress (Choi et al., 2016).

Table 3. Comparisons of stress, quality of life, knowledge for hypertension and horticulture for the horticultural therapy (HT) group and control group before the treatments in the study about horticultural therapy $(\mathrm{HT})$ program based on health care education for stress reduction of hypertensive patients.

\begin{tabular}{lcrc}
\hline \multirow{2}{*}{ Variables } & \multicolumn{2}{c}{ Control $(\mathrm{n}=30)$} & \\
\cline { 2 - 3 } & \multicolumn{2}{c}{ Mean (standard deviation) } & 0.8 \\
\hline Stress & $49.6(3.6)$ & $49.3(3.9)$ & 0.9 \\
Depression & $27.9(2.5)$ & $28.0(2.9)$ & 0.8 \\
Anxiety & $18.7(2.9)$ & $18.5(4.2)$ & 0.9 \\
Quality of life & $83.9(3.1)$ & $83.8(2.1)$ & 0.5 \\
Knowledge for hypertension & $1.8(1.8)$ & $1.5(1.5)$ & 0.6 \\
Knowledge for horticulture & $2.1(1.1)$ & $1.9(1.1)$ & 0.6 \\
\hline
\end{tabular}

${ }^{\mathrm{NS}}$ Non-significant at $p<.05$ by independent t-test.

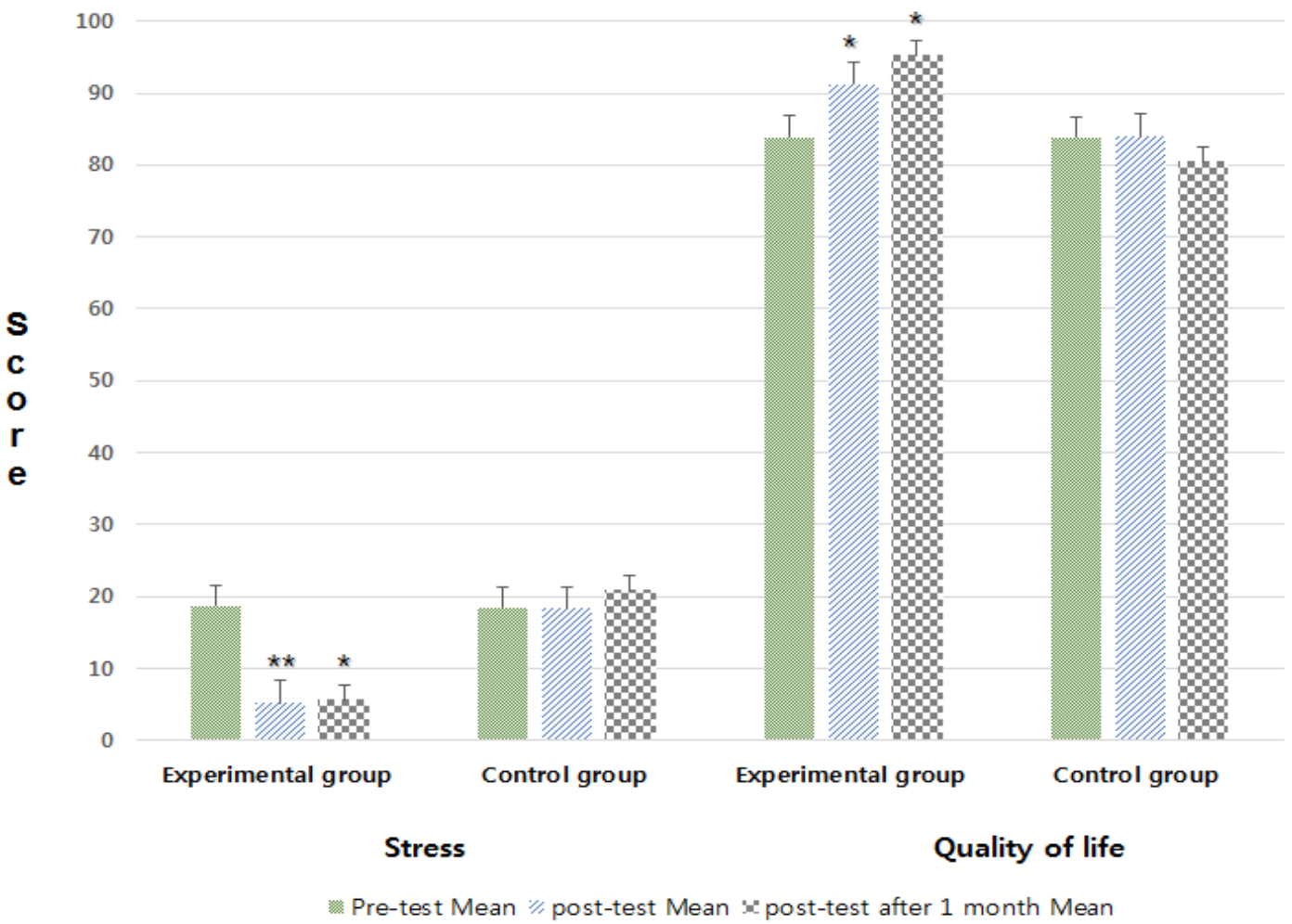

Fig. 1. Comparisons of stress and quality of life for the horticultural therapy group and control group after the treatments in the study about horticultural therapy program based on health care education for stress reduction of hypertensive patients. 


\section{(2) Quality of life}

The quality of life for the participants after the program and 1 month after improved significantly (Fig. 1). This indicates that this horticultural therapy program alleviates stress of hypertensive patients, and their participation in the leisure activity of horticulture improved their quality of life (Eom, 2009). Raising and tending plants cultivates positive thinking through constant communion with plants, and improve quality of life by giving composure and pleasure in life (Ulrich, 1986).

\section{(3) Depression, and anxiety}

The participants in this study showed an average of 27.87 and 27.97 points for the experimental and control group, respectively, when their depression was measured in the pretest, which exceeds 26 points that indicates no depression, thereby implying that changes in depression could not be measured through the experiment (data not shown). Cankurtaran et al. (2005) argued that depressed people show higher prevalence of hypertension, and depressive symptoms deteriorate hypertension.

Previous studies on hypertension and anxiety show that patients with cardiovascular diseases including hypertension face restraints in overall life and daily activities, and suffer from mental burden like psychological anxiety and depression (Lukkarinen and Hentinen, 1997). However, the participants in this study showed an average of 18.70 and 18.50 points (data not shown) for the experimental and control group, respectively, when their anxiety was measured in the pre-test. This is lower than the score obtained when Kim (1979) applied the STAI by Spielberger to Koreans, indicating that the participants showed no anxiety. Therefore, the effects could not be measured in this study.

2) Changes in knowledge of hypertension and horticulture among hypertensive patients

To measure the changes in knowledge of hypertension and horticulture among the participants in this study, questionnaires on a scale of 7 points were drawn up. In the pre-test, the experimental group scored 1.8 points for knowledge in hypertension and 2.1 points for knowledge in horticulture, whereas in the post-test, they scored 6.8 points for knowledge in hypertension and 6.6 points for knowledge in horticulture (data not shown). Furthermore, this level was maintained even 1 month after the program.

For example, in Session 1, the participants were asked to cut the stems of the plants and compare them to blood vessels, which enabled them to easily understand that hypertension is a vascular disease. Moreover, as they watched the cut-off plants, it was explained that their blood vessels can also be cut and injured if hypertension is neglected. Photosynthesis of plants is also explained to the participants as well as the complicated diagnosis of hypertension. They could better understand hypertension that is characterized by its lack of symptoms by showing the symptoms that may occur when plants are not tended properly. Furthermore, after the program, the subjects discovered that new shoots grew from the cut-off area of the stems from the plants used in Session 1, which changed their perception on managing hypertension through the regenerative power of plants.

3) Satisfaction survey on the horticultural therapy program based on health care education

For the overall satisfaction in the horticultural therapy program, $80 \%$ was very satisfied and $20 \%$ was satisfied, indicating that the participants showed high satisfaction in the program. For interest in activities, $100 \%$ was very interested, indicating that they showed high interest in the program based on health care education. This can be the baseline data for implementing horticulture in the current health care education programs. While subjects receiving only health care education may lack interest due to the dull learning structure of taking only health care materials, whereas those participating in the horticultural activity program can take the plants, which are outputs of horticultural activities, with them and constantly come up with feedback for the plants they planted themselves, which increased the level of interest in this program.

For the assessment of difficulty of health care education, $52 \%$ said it was slightly easy, $43 \%$ said it was average, $5 \%$ said it was slightly difficult. This shows that $95 \%$ said it was slightly easy or average, indicating that the difficulty of the health care education is average or higher. This supports the fact that it is suitable to use as the educational material for the horticultural therapy program implementing health care education on hypertension later. For difficulty of horticulture 
education, $23.3 \%$ said it was slightly easy, $65 \%$ said it was average, and $7.7 \%$ said it was slightly difficult. Thus, total $88.3 \%$ said it was slightly easy or average.

For preference of plants, Spathiphyllum was 36\%, Syngonium $25 \%$, Epipremnum aureum 25\%, and Dracaena 14\%, showing that the preference was around $25 \%$, which was an overall average. This indicated that the participants were satisfied with the horticultural activities in this program without one plant in particular having a biased effect on the entire program.

For preference of horticultural activities, planting flowers was $68 \%$, planting seeds $18 \%$, and cutting $14 \%$. Considering that the flower planting was done 5 times, seed planting 1 time and cutting 1 time out of total 7 sessions of horticultural activities, it could be found that the participants were generally satisfied with the horticultural activities in this program.

Lastly, for sustainability of horticultural leisure activities, $90 \%$ of the participants responded that they 'continue to participate in horticultural activities,' which proves that constant hypertension management can be made possible through horticultural leisure activities.

\section{Conclusion}

This study examined the effects of the horticultural therapy program applying health care education on stress, anxiety, depression and quality of life of hypertensive patients. After total 8 sessions of the horticultural therapy program, the stress levels of the hypertensive patients that participated in the program showed a decrease after the program and one month later, and their quality of life also improved. However, there was no significant difference in depression and anxiety of hypertensive patients in both the horticultural therapy group and the control group. Meanwhile, hypertensive patients that participated in the horticultural therapy program based on health care education showed an increase in the knowledge levels about horticulture and hypertension. The results of this study verified the potential for expanding the scope of application of the horticultural therapy program based on health care education, to help hypertensive patients manage stress and improve quality of life.

\section{References}

American Psychiatry Association. 2017. What is depression?, Retrieved from HYPERLINK "http//www.psychiatry.org/patients-families/" http://www.psychiatry.org/patients-families/depression/what-is -depression.

Bardage, C., D. Isacson, L. Ring, and K. Bingefors. 2003. A swedish population-based study on the relationship between the SF-36 and health utilities to measure health in hypertension. Blood Press. 12(4):203-210.

Beck, A.T., C.H. Ward, M. Mendelson, J. Mock, and J. Erbaugh. 1961. An inventory for measuring depression. Arch. Gen. Psychiatry 4(6):561-571.

Cankurtaran, M., M. Halil, B.B. Yavuz, N. Dagli, E.S. Cankurtaran, and S. Ariogul. 2005. Depression and concomitant diseases in a Turkish geriatric outpatient setting. Archives of Gerontology Geriatrics. 40(3):307-315.

Choi, J.Y., S.A. Park, S.J. Jung, J.Y. Lee, K.C. Son, Y.J. An, and S.W. Lee. 2016. Physiological and psychological responses of humans to the index of greenness of an interior space. Complementary Therapies in Medicine 28:37-43.

Clark, M.M., B.A. Warren, P.T. Hagen, B.D. Johnson, S.M. Jenkins, B.L. Werneburg, and K.D. Olsen. 2011. Stress level, health behaviors, and quality of life in employees joining a wellness centr. Am. J. Health Promot. 26(1):21-25.

Coleman, C.K. and R.H. Mattson. 1995. Influences of foliage plants of human stress during thermal biofeed back training. HortTechnology 5(2):137-140.

Doxon, L.E., R.H. Mattson, and A.P. Jurish. 1987. Human stress reduction through horticultural vocational training. HortScience 22(4):655-656.

Eom, A.Y. 2009. Influencing factors on health related to quality of life in hypertension patients. J. Korean Biol. Nurs. Sci. 11(2):136-142.

Forrette, F., M.L. Seux, and J.A. Staessen. 1998. Prevention of dementia in randomized double-blind placebo controlled systolic hypertension in Europe (Syst-Eur) trial. Lancet. 352(9137):1347-1351.

Ginty, A.T., A.C. Phillips, S.R. de Rooji, D. Carroll, and T.J. Roseboom. 2013. Depression and anxiety are associated with a diagnosis of hypertension 5 years later in a cohort of late middle-aged men and women. J. Hum. Hypertens. 27(3):187-190.

Han, K.S. 2003. Perceived stress, mood state, and symptoms of stress of the patient with chronic illness. J. Korean Acad. Nurs. 33(1): 87-94.

Hwang, J.H., B.S. Kang, S.H. Yun, S.B. Kim, and K.S. Lee. 2000. Health behaviors in hypertensive patients. Korean. J. Health Educ. Promot. 17(1):115-130.

Jang, K.O. 2003. The relationship among health habits, perceived health status and knowledge related to hypertension and medication compliances of hypertensive elderly. MS thesis, Catholic Univ. of Pusan. Busan, Korea.

Jang, K.O. 2016. Effects of public health center hypertension health school program on hypertension-related knowledge, self-care behavior, quality of life and physiological parameters in hypertensive patients. J. Kor. Academia-Industrial Cooperation Soc. 
17(11):236-247.

Jeon, J.H. and S.H. Kim. 2012. Depression, stress and how they are related with health behaviors and metabolic syndrome among women over 40 years. Korean Soc. Maternal and Child Health 16(2):263-273.

Jeong, S.H. and M.R. Huh. 2011. Study on the preferences of horticulture according to MBTI personality type in college students. J. Agric. Life Sci. 45(6):65-72.

Jo, H.S., C.B. Kim, H.W. Lee, and H.J Jeong. 2004. A meta-analysis of health related behavior study based on health belief model in Korean. Korean J. Health Psychol. 9(1):69-84.

Jo, K.N., D.S. Wang, and S.S. Kim, 1997. Personality characteristics, depression and anxiety for patients with essential hypertension. J. Korean Acad. Fam. Med. 18(1):65-77.

Jo, W.K. 2013. Application of welfare-horticulture to enhance the quality of life for the elderly in Korea. PhD Diss. Konkuk Univ., Seoul, Korea.

Kaplan, R. 1973. Some psychological benefits of gardening. Environ. Behav. 5(2):145-162.

Kim, J.T. 1979. Correlational research between trait anxiety-state anxiety and social skill - with Spielberger's theory of anxiety as the central figure -. J. Hum. Underst. Couns. 1:16-26.

Kim, M.K. 2011. Analysis on the effects of horticultural occupation therapy utilizing hospital roof garden. MS thesis, University of Seoul the graduate school. Seoul, Korea.

Kim, Y.S. 1997. Quality of life in diabetes managements. J. Kyung Hee Univ. Med. Cent. 13(1):7-15.

Koh, K.B. 1988. Stress perception of patients with psychosomatic disorders. J. Korean Neuropsyciatr. Ass. 27(3):514-522.

Korea Centers for Disease Control and Prevention. 2012. Standard educational guidelines (standardized PPTs and teaching manuals) for hypertension. Retrieved from http://cdc.go.kr/CDC/info/ CdcKrInfo0210.jsp?menuIds=HOME001-MNU1154-MNU07 25-MNU1375-MNU0566\&cid=19921

Korea Centers for Disease Control and Prevention. 2014. The national health and nutrition survey. Retrieved from https://knhanes.cdc. go.kr/knhanes/index.do

Korean National Statistical Office. 2012. Hypertension prevalence in Korea, Retrieved from www.index.go.kr

Kwon, H.S. 2012. Effect of horticultural therapy program on improvement of quality of life in rural elderly women. MS Thesis, Korea Univ., Sejong, Korea.

Lee, H.J. 2004. Effect of individual health education the medical clinic of public health centers on knowledge, self-efficacy, and self-care behavior in clients with hypertension. J. Korean Public Health Nurs. 18(1):80-89.

Lee, I.S. 2003. The literature review study for the nursing intervention and the effectiveness of the hypertension management programs. Graduate School of Public Health. Yonsei Univ. Seoul, Korea

Lee, J., C. Shin, Y.H. Ko, J. Lim, S.H. Joe, I.K. Jung, and C. Han. 2012. The reliability and validity studies of the Korean version of the perceived stress scale. Korean J. Psychosomatic Medicine 20(2): 127-134.

Lee, P.S. and K.S. Han. 2000. Symptoms of stress in essential hyper- tension. Korean Psychiatric and Mental Health Nursing Acad. Soc. 9(3):292-302.

Lee, S.J. 1998. Compliance with low-salt diet and related factors in essential hypertension patients. MS thesis, Seoul Natl Univ., Seoul, Korea.

Lee, Y.H. and J.Y. Song. 1991. A study of the reliability and the validity of the BDI, SDS, and MMPI-D scales. Korean J. Clini. Psychol. 10(1):98-113.

Li, J.J., C.H. Fang, and R.T. Hui. 2005. Is hypertension an inflammatory disease? Med. Hypotheses 64(2):236-240.

Lohr, V.I., C.H. Pearson-Mims., and G.K. Goodwin. 1996. Interior plant may improve worker productivity and reduce stress in window less environments. J. Environ. Horti. 14(2):97-100.

Lukkarinen, H. and M. Hentinen. 1997. Self-care agency and factors related to this agency among patients with coronary heart disease. International J. Nurs. Stud. 34(4):295-304.

Min, S.K., C.I. Lee, K.I. Kim, S.Y. Suh, and D.K. Kim. 2000. Development of korean version of WHO quality of life scale abbreviated version (WHOQOL-BREF). J. Korean Neuropsychiatr. Assoc. 39(3):571-579.

Ministry of Health and Welfare. 2014. Strengthen the management of preventing vascular diseases. Retrieved from http://www.mohw. go.kr/front_new/al/sal0301vw.jsp?PAR_MENU_ID=04\&MEN $\mathrm{U}$ ID $=0403 \& B O A R D \_I D=140 \& B O A R D \_F L A G=00 \& C O N T$ SEQ $=300682$ \&page $=1$

Moore, B. 1989. Growing with gardening. The University of North Carolina Press, North Carolina, USA.

Nine, S.L., C.L. Lakies, H.K. Jarrett, and B.A. Davis. 2002. Communitybased chronic disease management program for African Americans. Outcomes Manag. 7(3):106-112.

Oh, K.O., M.H. Kang, and K.S. Jung. 2012. Effects of horticultural therapy program on state-anxiety, fatigue and quality of life among women cancer survivors. Asian Oncol. Nurs. 12(2):125-131.

Owen, P. 1994. The influence of a botanic garden experience on human health. MS Thesis, Kansas State University, Manhattan, USA.

Park, K.M., H.S. Kim, K.S. Kim, and E.S. Park. 1992. The comparison of quality of life between hypertension patients nad normal control sudjects. J. Korean Acad. Fam. Med. 13(3):240-245.

Park, S.A., M.K. Cho, M.H. Yoo, S.Y. Kim, E.A. Im, J.E. Song, J.C. Lee, and I.G. Jun. 2016. Horticultural activity program for improving emotional intelligence, prosocial behavior, and scientific investigation abilities and attitudes in kindergarteners. HortTechnology 26(6):754-761.

Saboya, H.P., P.R. Zimmermann, and L.C. Bodanese. 2010. Association between anxiety or depressive symptoms and arterial hypertension, and their impact on the quality of life. Int. J. Psychiatr. Med. 40(3):307-320.

So, E.S. and I.S Lee. 2010. Meta-analysis of hypertension-related nursing invention programs. J. East-west Nurs. Res. 16(1):11-18.

Spielberger, C.D., R.L. Gorsuch, and R.E. Lushene. 1970. Manual for the State-Trait Anxiety Inventory. Consulting Psychologist Press, Palo Alto, California.

Ulrich, R.S. 1986. Human responses to vegetation and landscapes. Landsc. Urban. Plan. 13:29-44. 